\title{
Adaptation of AIR Self-Determination Scale - Educator Version to Turkish (AIR SDS-TR)
}

\author{
Received \\ Revised \\ Accepted \\ $\mathrm{DOI}$
}

Ali Kaya ${ }^{a, *}$, Mustafa Kemal Yöntem ${ }^{b}$

*This research was supported by The Scienfic and Technological Research Council of Turkey (TUBITAK) 2219 Program.

"Corresponding Author: Ali Kaya,

Special Education Department, Nevşehir Hacı Bektaș Veli University, Nevşehir, Turkey

E-mail: alikayya@gmail.com

ORCID: https://orcid.org/0000-0002-9235-8231

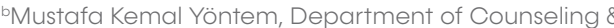
Guidance, Nevşehir Hacı Bektaş Veli University, Nevşehir, Turkey

E-mail: muskemtem@hotmail.com

ORCID: https://orcid.org/0000-0001-7620-0971

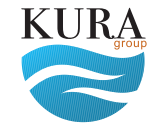

Copyright (a)

Www.iejee.com

ISSN: 1307-9298

(C) 2021 Published by KURA Education \& Publishing. This is an open access article under the CO BYNC- ND license. (https://creativecommons.org/ licenses/by/4.0/)

\begin{abstract}
The purpose of this study is to adapt Adaptation of AIR SelfDetermination- Educator Version The confirmatory factor analysis (CFA) of the scale, which was translated into Turkish and studied in terms of language validity, was carried out on 220 (46.8\% female, 53.2\% male) special education teachers. Teachers answer the items in the scale by thinking about their students. The age range of the participants in the study was between 25 and 59, and the mean age was 36.12 (sd \pm 7.03). Sixty-four percent of the students reflected by the data in the study were female and thirty-six percent were male. According to the distribution of the disability groups, $24 \%$ of the students had autism and $76 \%$ had an intellectual disability. After establishing language, the validity and reliability of the scale of analysis was examined. Item-factor structure has been tested for compliance with a model by confirmatory factor analysis (CFA). Based on this, five-factor structure of Adaptation of AIR Self-Determination Scale - Educator Version has been validated. As a result of the analysis for adaptation of Adaptation of AIR SelfDetermination Scale - Educator Version to Turkish, it can be said that the scale is a reliable and valid measurement tool. As a result of the measurement model, the t values of the indicators in the measurement model were between 10.02 and 16.36 and R2 values varied between .39 and .78. Cronbach's Alpha $(\alpha)$ internal consistency coefficient of the scale ranged between .86 and .94 . The CR values of the subdimensions of the scale vary between .86 and .93, and the AVE values between .51 and .70 .
\end{abstract}

\section{Keywords:}

Self-Determination; Special Education; Intellectual Disability Autism

\section{Introduction}

In today's world, all people have the right to make decisions about their own lives, which is one of the most natural facts. Undoubtedly, not all people are the same, and just as each person has individual differences, some people also have special needs. Individuals with intellectual disability, who are among groups that have special needs, also have the right to self-determination. Self-determination refers to a person's taking responsibility for their own life (Zhang \& Benz, 2006). According to Wehmeyer (1992), 


\section{iejee}

self-determination is the body of attitudes and skills required for an individual to act independently of external influences and interventions and to make choices about their own actions as the primary subject in their own life. To achieve these skills, the individual must (a) act autonomously, (b) regulate their own behaviour, (c) initiate and respond to actions with psychological resilience, and (d) exhibit behaviours in a self-fulfilling manner (Wehmeyer, 1997). Self-determination is a versatile skills that includes positive competencies, such as making choices, decision-making, problem-solving, goal setting, goal achievement, self-observation, self-reinforcement, self-defense, and leadership (Wehmeyer, 1999; Martin et al., 1995). According to another definition, selfdetermination is the body of skills, knowledge, and beliefs that enable the individual to engage in goaloriented, self-regulating, and autonomous behaviors. To achieve self-determination, it is necessary that individuals know their strengths and limits as well as having the belief that they are capable and effective. When individuals have these skills, they may have more opportunities to control their own lives and to take on the role of successful adults in the society they live in (Field et al., 1998). Both environmental and individual characteristics contribute to the development of self-determination. Individual skills that affect learning and development, opportunities caught by environments and experiences, supports, and arrangements all affect the emergence of selfdetermination (Wehmeyer, 1997, 2003). According to Wehmeyer (2007), when individuals can use their selfdetermination skills, they become the primary guiding person of their own life.

Positive psychology involves the pursuit of understanding optimal human functioning and well-being and a prominent construct in positive psychology is self-determination (Deci and Ryan 2002). Research in self-determination in positive psychology has focused on the construct in the context of motivational psychology, and while research and theory in self-determination in special education was derived from Deci Ryan's early work, most of the theoretical perspectives within special education have focused more broadly on selfdetermination as, in essence, a personality construct and less specifically on motivational aspects pertaining to self-determination (Shogren et al., 2015). The topic of self-determination has been extensively studied in the education of students with special needs since the early 1990s (Shogren, et al., 2008). Teaching students with special needs how to achieve self-determination is considered the best practice possible (Field \& Hoffman, 2002), and this teaching is extremely important, especially for adult life. However, there is evidence that individuals with intellectual disability can achieve self-determination when they are provided with adequate support (Wehmeyer et al., 2003). It is known that adequate supports and self-determination practices increase the academic performance (Konrad, Fowler,Walker, Test,\&Wood, 2007; Raley, Shogren, \& McDonald, 2018), make leisure time activities more qualified (Dattilo \& Rusch, 2012) of students with special needs in the post-school period, and increase the quality of life of adults with special needs (Lachapelle et al., 2005).

\section{Cultural differences}

People become a part of the culture they live in, and this culture affects them directly or indirectly. According to Shogren (2011), people in eastern cultures may be more dependent on family goals rather than individual goals when pursuing self-determination. In Western cultures, on the other hand, more emphasis is placed on individuality. In western countries, for example, those in North America, Europe, and Australia, people's autonomy, personal space, and individual choices are more important (Wong et al., 2011). Based on this, it can be said that individuals with intellectual disabilities living in western countries have more cultural opportunities to develop selfdetermination skills compared to those with intellectual disabilities living in eastern countries. Although various measurement tools have been developed to measure self-determination skills in the field of intellectual disabilities, only the Arc's Self-Determination Scale, developed by Wehmeyer \& Kelchner (1995), and the AIR, (Wolman et al., 1994), which is the measurement tool of American Research Institute, were designed to measure self-determination globally. The AIR SelfDetermination Scale had previously been translated into Spanish (Mumbardó, Guàrdia Olmos, \& Giné, 2018), Norwegian (Garrels, \& Granlund, 2018), and Chinese (Wong, et al., 2017). However, there is not enough research on the appropriateness and application of self-determination skills to students with different linguistic and cultural backgrounds. For this reason, it is extremely important to use measurement tools that can determine the extent to which individuals with intellectual disabilities can employ their selfdetermination skills. With this purpose in mind, the Turkish adaptation study of the educator version of the AIR scale was carried out in this study. In addition, self-determination studies of individuals with special needs are currently very limited in Turkey (Orum-Çattık, 2020), and considering this limitation, it is thought that this study will contribute both to the field of special education and to new policies to be produced for individuals with intellectual disabilities.

\section{Method}

In this part of the study, detailed information on the study group, data collection, data collection tools, the process, and data analysis was presented. 


\section{Study Group}

The study data were collected from special education teachers. In this context, the teachers were asked to answer questions by considering a student they were already teaching. Therefore, two different working groups can be mentioned. We can define these groups as the study group that the data were collected from and the group that was reflected by the data. Within the scope of the validity and reliability study of AIR SDS-TR, data were collected from seven different geographical regions of Turkey. The confirmatory factor analysis (CFA) of the scale, which was translated into Turkish and studied in terms of language validity, was carried out on 220 (46.8\% female, 53.2\% male) special education teachers. The age range of the participants in the study was between 25 and 59, and the mean age was 36.12 ( $s d \pm 7.03$ ). Sixty-four percent of the students reflected by the data in the study were female and thirty-six percent were male. According to the distribution of the disability groups, $24 \%$ of the students had autism and $76 \%$ had an intellectual disability. Demographic data are shown in table 1.

Table 1.

Demographic data on participants

\begin{tabular}{lll} 
& Teacher & Student \\
Women & $46.8 \%$ & $64 \%$ \\
Man & $53.2 \%$ & $36 \%$ \\
Age (Avg) & 36,12 & $15,2 \%$ \\
Bachelor & $97 \%$ & \\
MD & $3 \%$ & \\
ID & & $76 \%$ \\
ASD & & $24 \%$ \\
\hline
\end{tabular}

\section{Data Collection}

During the data collection process, first, necessary permission was obtained for the use of the measurement tools in the study. For this purpose, Dr. Dennis Mithaug was contacted through the web site of the University of Oklahoma Zarrow Center regarding the measurement tool. In addition, ethical and legal approval of Nevşehir $\mathrm{Hacl}$ Bektaş Veli University was obtained to collect data. During the data collection process, an informed consent form was added to the data collection tool to inform the participants about the purpose and content of the study and to ensure the voluntary participation of all participants in the study. Also, a personal information form was used together with the measurement tools. The administration of data collection tools took an average of 10-15 minutes for each participant.

\section{Data collection tools}

The study data were collected using the AIR SelfDetermination Scale- Educator Version (A) Turkish
Version and a Personal Information Form. Detailed information about these data collection tools is given below.

The personal information form: This form was used to collect socio-demographic data about the participants and to obtain information about the study group. This form was created by the researchers to determine the sex, grade, and age of the teachers in the study group and the undergraduate program they graduated from.

The AIR Self-Determination Scale - Educator Version: There is evidence that self-determination skills are important for young people with special needs so that they can achieve more successful educational outcomes and reach adult life (Wehmeyer \& Schwartz, 1997). Therefore, measuring self-determination skills is important. The AIR Self-Determination Scale was developed by Wolman, Campeau, DuBois, Mithaug, and Stolarski (1994). This scale was designed on three concepts: thinking, doing, and adjusting. It was stated that the evaluation results of this tool, which was developed by Wolman et al. to determine the level of self-determination in individuals with special needs, could reveal basic information for teachers as in individualized education programs of students. The AIR Self-Determination Scale is suitable for all students with and without special needs from primary school to university level. There are three versions of the scale, including educator form, parent form, and student form. The educator form consists of 30 questions that evaluate students' level of self-determination and self-determination characteristics. This form can also evaluate opportunities for self-determination provided by those with whom the student shares important relationships. In this study, the Turkish adaptation study of the educator version of the scale was conducted.

\section{The Implementation Process of The Study}

AIR SDS Educator Version is a tool that can be used by all educators. In the process of adapting AIR SDS-TR to Turkish, the scale was first translated into Turkish. The translation process was carried out in two stages. First, the scale was translated into Turkish by the researchers. Then, the items on the scale were translated independently by 7 experts, including 3 from the field of translation and interpretation, 2 from the field of Guidance and Psychological Counselling (GPC), and 2 from the special education field. The translations obtained at this stage were compared and those which were evaluated to best reflect the related scale items were determined. Next, a draft form was obtained and it was piloted to 10 participants (special education teacher) individually to test the intelligibility of the items on the scale. Finally, a consensus was reached on the final form of the Turkish form of the scale by the researchers for the language validity study. 


\section{iejee}

\section{Data Analysis}

In the study process, first of all, analyses regarding the adaptation process of the measurement tool were conducted. Accordingly, descriptive statistics related to the demographic characteristics of the participants, and Confirmatory Factor Analysis (CFA) and Cronbach's Alpha $(\alpha)$ internal consistency coefficient analyses were employed for the validity and reliability values of the measurement tools. Prior to the study, missing values of the data set were entered by determining the average scores for the dimensions. Afterwards, the multivariate normality of data distribution was examined by Mardia's test. The result of analysis showed that the Mardia's Skewness was 93.53 ( $p$ <.001), and Mardia's Kurtosis was 35.11 ( $p<.001)$. That means the multivariate normality requirement was not met and data were not normally distributed. Since Maximum Likelihood estimation is recommended to utilize in the existence of multivariate normality (Kline, 2011), Maximum Likelihood Robust estimation was utilized throughout the present study. The data were analysed using the SPSS 24.00, RStudio (Version 1.4.1717), and LISREL 9.1 software packages. In RStudio, MVN package was used to run Mardia's test.

Results

A first-order CFA analysis was conducted in the first stage. The validity of the 30-item and 5-factor scale was tested with the confirmatory factor analysis. For the validity, first-order CFA was executed using the maximum likelihood robust estimation method in this phase, confirmatory factor analysis was carried out with the data set ( $n=220$ ) without making any modifications. After confirmatory factor analysis, acceptable fit indexes were obtained for the fivefactor structure (Table 1)

Figure 1. Standard load values for AIR-S' correlated factors model

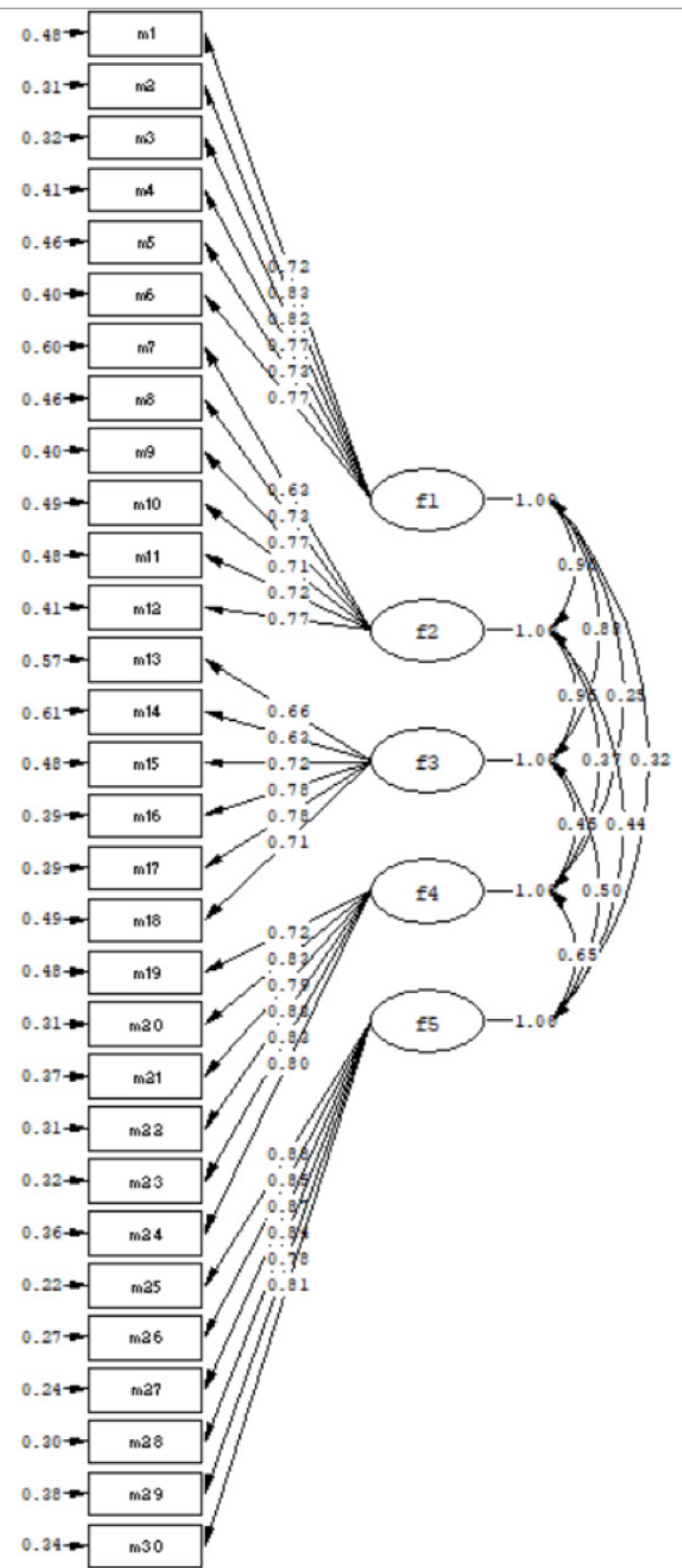

Chi-Scruare $=739.33, d f=395, \mathrm{P}-\mathrm{val}$ ue $=0.00000, \mathrm{RMSEA}=0.063$ 
Table 1.

The goodness of fit indices obtained as a result of the correlated factors model

\begin{tabular}{lrr}
\hline Indices & Acceptable fit & Model indices \\
\hline$\chi^{2} /$ df & $\leq 3$ (Hair et. al., 2006) & 1.87 \\
RMSEA & $\leq .08$ (Hair et. al., 2006) & 0.06 \\
SRMR & $\leq .08$ (Hair et. al., 2006) & 0.05 \\
NFI & $\geq .90$ (Hair et. al., 2006) & 0.95 \\
NNFI & $\geq .90$ (Hair et. al., 2006) & 0.98 \\
CFI & $\geq .90$ (Hair et. al., 2006) & 0.98
\end{tabular}

Some of the fit values were taken as a reference to evaluate the statistical fit of the model. To determine the goodness of fit of the model in this study, the frequently used criteria, such as $X^{2}$ / df value, nonnormed fit index (NNFI), the root-mean-square error of approximation (RMSEA), comparative fit index (CFI), and standardized root mean square residual (SRMR) were used. As seen in Table 1 and, according to the CFA results obtained without any modifications on the data, the fit indices were generally in the range of perfect fit values (Hair et. al., 2006). In addition, as can be seen in Figure 1, the standard load values for the items were at acceptable levels.

An important criterion that reveals the importance of the observed variable in terms of the latent variable is the $\mathrm{R}^{2}$ value, which shows how much each observed latent variable can explain the variance in the variable (Tabachnick \& Fidell, 2007). Standardized values and $\dagger$ and $R^{2}$ values of AIR Self-Determination Scale-Educator Version are given in Table 2. Finally, to reveal the reliability values of the scale, itemtotal correlations, average variance extracted (AVE), composite reliability (CR) and the Cronbach $\alpha$ values of the sub-dimensions were examined. These values are presented in Table 2

Table 2.

Values for items and factors obtained as a result of the correlated factors model

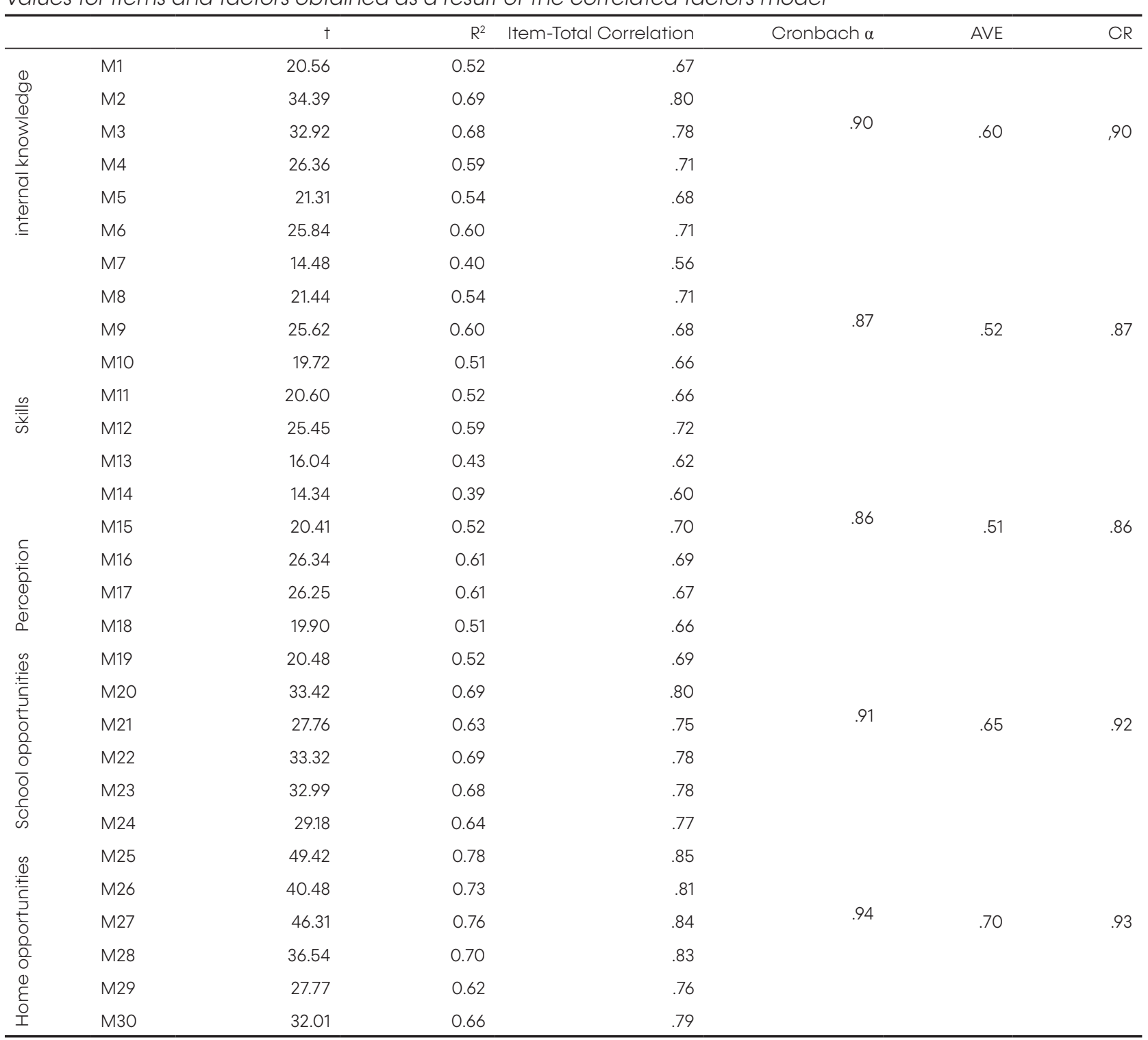




\section{iejee $\approx$}

As seen in Table 2, the examination of + values of the model indicated that all observed variables could be predicted by the latent variable at a significance level of .01 Also, as a result of the measurement model, the $t$ values of the indicators in the measurement model were between 10.02 and 16.36 and $R^{2}$ values varied between .39 and .78. Cronbach's Alpha $(\alpha)$ internal consistency coefficient of the scale ranged between .86 and .94 . The CR values of the sub-dimensions of the scale vary between .86 and .93, and CR value of whole scale was .89. The AVE values between .51 and .70.

\section{Discussion}

This study aimed to confirm the Turkish version of the educator form of the AIR-Scale and to discover the differences in the distribution of sub-dimensions among children with special needs. The original form of the scale consists of 5 sub-dimensions named internal knowledge, skills, perception, school opportunities, and home opportunities. The findings obtained within the scope of the study revealed that the measurement model, which was consistent with the original factor structure, was also supported in the Turkish culture. In the adaptation study of the AIRScale Educator Form, it was observed that the fivedimensional structure of the scale was confirmed. The dimensions were named knowledge, skills, perception, school opportunities, and home opportunities, as in the original form.

Moreover, acceptable internal consistency values were obtained. When the absolute goodness of fit indices of the confirmatory factor analysis are examined, it will be seen that the $X^{2} / d$ f ratio is below 3 . This indicates a very good model fit (Hair et. al., 2006; Kline, 2016). RMSEA was found to be 0.06. While Hair et al. (2006) state that this value should be less than or equal to .80. Similarly, according to Kline (2016), SRMR value less than or equal to .10 is considered sufficient. Tabachnick and Fidell (2007) and Hair et al. (2006) state that the SRMR value should be less than or equal to .08. The SRMR value of the scale complies with these criteria (SRMR<.08). GFI and AGFI values were also above 09 (Hair et. al., 2006; Kline, 2005). Similarly, when the relative fit indices (NFI, NNFI) are examined, it will be seen that the values are above .90 . When all these findings are considered together, it will be seen that goodness of fit indices indicate good fit.

There are different opinions in the literature about how much the item-total correlation should be. While Büyüköztürk (2007) stated that this value should be above .30, Karasar (1995) stated that this value should be above .50. When the item-total correlations of the scale are examined, it will be seen that all of them are above .50. When the reliability values of the scale are examined, Cronbach's Alpha $(\alpha)$, AVE and CR values indicate that the scale is a reliable scale (Fornell \& Larcker, 1981). When all these findings are considered together, it can be thought that the Turkish version of the educator form of the scale is a reliable and valid measurement tool.

A literature review indicated that the educator form of the scale, which was adapted to the Turkish language in this study, was not adapted to different languages. However, according to the literature, the student form of the AIR-Scale had previously been adapted to Turkish and the sub-dimensions had yielded results that were consistent with the original form (Arslan \& Özmete, 2015). Similarly, it was found that the Spanish (Mumbardó, Guàrdia Olmos, \& Giné, 2018), Norwegian (Garrels, \& Granlund, 2018), and Chinese (Wong, et al., 2017) versions of the scale had also yielded results that were consistent with the original scale.

\section{Limitations and further research}

It should be kept in mind that the sample group is limited as the data set consists of a study group of 220 people. In addition, data were collected only from teachers of individuals with special needs. For this reason, necessary statistical analyses should be conducted so that the scale can be administered to individuals with typical development. It should be stated that the research only covers individuals with special needs, which is another important limitation. In future studies, it will be useful to test the scale with individuals with typical development. Besides, the relationship between the self-determination levels of individuals with special needs and different variables can be analysed by using this scale. As far as it is known, the family form of the scale has not been adapted to Turkish culture, yet. It will be useful to conduct the adaptation study of this form in future studies, too.

\section{Conclusions}

In line with the research findings, it can be stated that it would be useful to use the Turkish form of the scale to evaluate the self-determination levels of the students of special education teachers. In addition, experimental studies can be conducted to reveal how much training programs to be developed can improve the level of self-determination. Furthermore, descriptive studies can be conducted to guide policymakers by conducting screening programs on self-determination in special education centers. Studies carried out for this purpose at micro and macro levels can contribute to the development of appropriate policies.

\section{References}

Arslan, D. T., \& Özmete, E. (2015).Yetiştirme yurtlarında kalan ve ortaöğretime devam eden öğrencilerin self-determinasyon davranışları. Sosyal Politika Çalışmaları Dergisi, 35, 53-78. 
Büyüköztürk, S.. (2007). Sosyal bilimler için veri analizi el kitabı. 8. Basım. Pegem Yayıncılık

Field, S., \& Hoffman, A. (2002). Development of a model for self-determination. Career Development for Exceptional Individuals, 17, 159-169. https://doi. org/10.1177/088572889401700205

Field, S., Martin, J., Miller, R., Ward, M., \& Wehmeyer, M. (1998). A Practical Guide for Teaching SelfDetermination. CEC Publications.

Fornell, C., \& Larcker, D. F. (1981). Evaluating structural equation models with unobservable variables and measurement error. Journal of marketing research, 18(1), 39-50.

Garrels, V., \& Granlund, M. (2018). Measuring selfdetermination in Norwegian students: adaptation and validation of the AIR SelfDetermination Scale. European Journal of Special Needs Education, 33(4), 466-480. https:// doi.org/10.1080/08856257.2017.1342420

Karasar, N. (1995). Bilimsel araştırma yöntemi. Kavramlar, ilkeler, teknikler. 3A Araştırma, Eğitim, Danışmanlık.

Karvonen, M., Test, D. W., Wood, W. M., Browder, D., \& Algozzine, B. (2004). Putting self determination into practice. Exceptional Children, 71, 23-41. https://doi.org/10.1177/001440290407100102

Kline, R.B. (2016). Principles and practice of structural equation modeling ( $4^{\text {th }}$ Edition). Guilford Press

Martin, J. E., \& Marshall, L. H. (1995). Choice Maker: A comprehensive self determination transition program. Intervention in School and Clinic, 30(3), 147-56. https://doi. org/10.1177/105345129503000304

Mumbardó, C., Guàrdia Olmos, J., \& Giné, G. (2018). Assessing self-determination in youth with and without disabilities: The Spanish version of the AIR self-determination scale. Psicothema, 30(2), 238-243.

Shogren K. A. (2011) Culture and self-determination: a synthesis of the literature and directions for future research and practice. Career Development and Transition for Exceptional Individuals 34, 115-27. https://doi.org/10.1177/0885728811398271
Shogren, K. A., Wehmeyer, M. L., Palmer, S. B., Soukup, J. H., Little, T. D., Garner, N., \& Lawrence, M. (2008). Examining the relationship between the Arc's Self-Determination Scale the American Institutes for Research Self-Determination Scale. Assessment for Effective Intervention, 33(2), 94107.

Tabachnick, B. G., Fidell, L. S., \& Ullman, J. B. (2007). Using multivariate statistics. Pearson.

Wehmeyer M. L. \& Kelchner K. (1995) The Arc's Selfdetermination Scale. Arc National Headquarters, TX.

Wehmeyer, M. L., Abery, B. H., Mithaug, D. E., \& Stancliffe, R. J. (2003). Theory in self-determination: Foundations for educational practice. Charles C Thomas Publisher.

Wehmeyer, M. (1997). Self-directed learning and self-determination. In M. Agran (Ed.), Studentdirected learning: teaching self-determination skills (pp. 28-59). Brooks/Cole

Wehmeyer, M. L. (1992). Self-determination and the education of students with mental retardation. Education and Training in Mental Retardation and Developmental Disabilities, 27, 302-314

Wehmeyer, M. L. (1999). A functional model of selfdetermination: Describing development and implementing instruction. Focus on Autism and Other Developmental Disabilities, 14, 53-61. https://doi.org/10.1177/108835769901400107

Wehmeyer, M. L. (2003). A functional theory of self-determination: Model overview. In M. L. Wehmeyer. B. Abery, D. E. Mithaug, \& R. StanclifFe (Eds.). Theory in self-determination: Foundations for educational practice. Charles $\mathrm{C}$ Thomas.

Wehmeyer, M. L. (2007). Promoting Self-Determination in Students with Developmental Disabilities. Guilford Press.

Wehmeyer, M. L., \&. Schwartz, M. (1997). Self determination and positive adult outcomes: A follow-up study of youth with mental retardation and learning disabilities. Exceptional Children, 63, 245-255. https://doi. org/10.1177/001440299706300207

Wolman, J. M., Campeau, P. L., DuBois, P. A., Mithaug, D. E., \& Stolarski, V. S. (1994). AIR Self-Determination Scale and User Guide. American Institutes for Research. 
Wong P. K. S., Wong D. F. K., Schalock R. L. \& Chou Y. C. (2011). Initial validation of the Chinese quality of life questionnaire - intellectual disabilities (CQOL-ID): a cultural perspective. Journal of Intellectual Disability Research 55, 572-80. https://doi.org/10.1111/j.1365-2788.2011.01412.x

Wong, P. K. S., Wong, D. F. K., Zhuang, X. Y., \& Liu, Y. (2017). Psychometric properties of the AIR SelfDetermination Scale: the Chinese version (AIR SDS-C) for Chinese people with intellectual disabilities. Journal of Intellectual Disability Research, 61(3), 233-244. https://doi.org/10.1111/ jir.12343

Zhang, D., \& Benz, M. R. (2006). Enhancing selfdetermination of culturally diverse students with disabilities: Current status and future directions. Focus on Exceptional Children, 38(9), 1-12.

Shogren, K. A., Wehmeyer, M. L., Palmer, S. B., ForberPratt, A. J., Little, T. J., \& Lopez, S. (2015). Causal Agency Theory: Reconceptualizing a functional model of self-determination. Education and Training in Autism and Developmental Disabilities, 50(3), 251-263.

Deci, E. L., \& Ryan, R. M. (2002). Handbook of selfdetermination research. Rochester, NY: University of Rochester Press.

Konrad, M., Fowler, C. H.,Walker, A. R., Test, D.W.,\& Wood,W. M. (2007). Effects of self-determination interventions on the academic skills of students with learning disabilities. Learning Disability Quarterly, 30, 89-113.

Raley, S. K., Shogren, K. A., \& McDonald, A. (2018). Wholeclass implementation of the Self-Determined Learning Model of Instruction in inclusive high school mathematics classes. Inclusion, 6(3), 164174.

Dattilo, J., \& Rusch, F. (2012). Teaching problem solving to promote self-determined leisure engagement. Therapeutic Recreation Journal, 46, 91-105.

Lachapelle, Y., Wehmeyer, M. L., Haelewyck, M. C., Courbois, Y., Keith, K. D., Schalock, R.,. . . Walsh, P. N. (2005). The relationship between quality of life and self-determination: An international study. Journal of Intellectual Disability Research, 49, 740-744.

Orum-Çattık, E. (2020). Young Adults with Autism Spectrum Disorder Preparing for Independence the Effects of the Self-Determination Learning Model of Instruction. Master diss., Anadolu University. 